\title{
Canada-US border air quality strategy (BAQS): preliminary results of mortality and cancer incidence in Windsor, Canada
}

\author{
P. R. Band ${ }^{1}$, J. M. Zielinski ${ }^{1}$, H. Jiang ${ }^{1} \&$ L. Liu ${ }^{2}$ \\ ${ }^{1}$ Division of Biostatistics and Epidemiology, \\ ${ }^{2}$ Air Health Effects Research Section, \\ Healthy Environments and Consumer Safety Branch, Health Canada, \\ Ottawa, Canada
}

\begin{abstract}
Windsor is one of the main Canadian cities exposed to transborder air pollution and part of the BAQS. We have analyzed all causes of mortality and cancer incidence in Windsor for the period 1979 to 1999 in comparison to provincial (Ontario) rates, using age-adjusted standardized mortality (SMRs) and standardized incidence (SIRs) ratios. In the age group 20 years and over and in both males and females, statistically significantly increased SMRs and SIRs were observed for diseases that have been associated with long-term air pollution exposure: mortality from circulatory diseases, bronchitis and emphysema, and lung cancer; lung cancer incidence. These results suggest a potential risk associated with air pollution exposure, but present the limitations inherent to mortality and cancer incidence studies. The results of further planned studies assessing these health outcomes to areas of exposure to air pollution within Windsor will be needed to provide stronger evidence to these preliminary findings.
\end{abstract}

Keywords: air pollution, mortality, circulatory diseases, bronchitis and emphysema, lung cancer incidence.

\section{Introduction}

Excess mortality related to severe air pollution has been well documented during the Meuse Valley, London and Donora fog episodes (Firket [1], Ciocco and 
Thompson [2], Logan and Glasg [3]). Since, adverse health effects of lower levels of air pollution have been reported; time series studies have shown relationships between total mortality from natural causes and from cardiorespiratory diseases (Schwartz [4, 7], Swartz and Dockery [5, 6], Kinney and Özkaynak [8], Dockery et al. [9], Samet et al. [10]), as well as increased hospital admissions for respiratory diseases and congestive heart failure (Lipfert and Hammerstrom [11], Burnett et al. [12, 13], Morris et al. [14]). These events have been attributed mainly to exposure to particulates including British smoke (Schwartz and Marcus [15]), total suspended particles (Schwartz [4]. Schwartz and Dockery [5, 6]) $\mathrm{PM}_{10}$ (Dockery et al. [9], Schwartz [7], Samet et al. [10]), $\mathrm{PM}_{2.5}$ (Dockery et al. [9]) and to sulfate particulates (Lipfert and Hammerstrom [11], Burrnett et al. [13]). In addition, relationships between sulfur dioxide (Lipfert and Hammerstrom [11]), ozone (Lipfert and Hammerstrom [11], Burnett et al. [12]) and respiratory morbidity, and between carbon monoxide (Morris et al. [14]) and hospitalization for congestive heart failure have been noted. Similarly, cardiorespiratory diseases have been associated with long-term air pollution exposure to inhalable and fine particulates (Dockery et al. [16], Pope et al. [17, 18], Hoek et al. [19], Nafstad et al. [20]). As opposed to time-series studies, long-term exposure to air pollution particulates (Dockery et al. [16], Pope et al. [17, 18], Beeson et al. [21]), nitrogen dioxide (Nyberg et al. [22]) and nitrogen oxides (Nafstad et al. [20,23]) has been associated with an increased lung cancer risk.

In January 2003, the Governments of Canada and of the United States launched the Canada-US Border Air Quality Strategy (BAQS) to assess health effects of populations exposed to air pollution in these border regions. These activities combine evaluation of health effects and community and personal exposure assessments. With respect to health research initiatives, the CanadaUS Border Air Quality Strategy established the following key objectives: collecting human health data in support of the identified regional pilot; analyzing evidence of human health impacts from air pollution in the regional airshed; assessing the risk to human health posed by air pollution.

The Eastern Canada regional airshed pilot includes Essex County, a census division largely made up by the census metropolitan area of Windsor. This municipality, situated in the most southern part of the Province of Ontario is of particular concern with respect to cross-border airborne pollution because of its proximity to the city of Detroit, U.S.A., and because of traffic pollution with about 10000 trucks crossing each day the bridge linking Windsor to Detroit.

The Air Quality Research Division and the Biostatistics and Epidemiology Division, Safe Environments Programme, Health Canada are conducting epidemiologic studies to investigate health effects of the identified regional pilot area of concern. It was proposed that health effects studies proceed in two phases. In a first phase, mortality rates for all causes of death and cancer incidence rates would be analysed. In a second phase, death and cancer incidence rates would be investigated in relation to air pollution distribution within the urban areas of concern. The latter entails geocoding of the data not 
only for assessing spatial relationships between health outcomes and air pollution levels but also to evaluate these outcomes by socio-economic indices.

This first report, which fulfils BAQS first objective of collecting human health data, presents mortality and cancer incidence rates for Essex County, for the period 1979-1999.

\section{Method}

The databases of age-adjusted mortality and cancer incidence rates for the years 1979 to 1999 inclusive were obtained from the Ontario Cancer Registry, Cancer Care Ontario. Population data were obtained from Statistics Canada for the decennial and quinquenial census of 1971, 1976 and thereafter up to 2001. Person-years were calculated for males and females by five-year age groups and five-year calendar periods. Mortality was assessed using standardized mortality ratios (SMR), which are the ratios of the observed number of deaths in Essex County to the expected values calculated by applying the reference population sex, age, calendar year and cause specific mortality rates to the population person-years distributions of each study areas. Ontario population rates were used as reference to generate expected number of deaths. Cancer incidence was assessed similarly using standardized cancer incidence ratios (SIR), which are the ratios of the observed number of cancer incident cases in Essex County to the expected values calculated by applying the reference population sex, age, calendar year and cause specific incidence rates to the population person year distribution of each study areas. Two-sided $95 \%$ confidence intervals for the SMR and SIR were calculated under the assumption that the observed number of deaths followed a Poisson distribution (Breslow and Day [24]). The Poisson chisquare trend and heterogeneity-test statistic (Breslow and Day [24]) were used to test whether SMR or SIR ratios were significantly higher in Essex County compared to Ontario provincial rates. Causes of death were coded under 20 categories according to the 9th revision of the International Classification of Diseases (World Health Organization [25]). Cancer topography and morphology were coded according to the International Classification of Diseases for Oncology (ICD-O) [26].

\section{Results}

The mean annual population of Essex County over the study period was 335, 710 , with the census metropolitan area of Windsor accounting for $82 \%$ of this population. For the age groups 0 to 14 years and 0 to 19 years, no significantly increased mortality was observed for respiratory diseases (ICD- 9 codes 460519 ) and asthma (ICD-9 code 493). Results of mortality from circulatory and respiratory diseases and for lung cancer incidence are presented in Tables 1, 2 and 3 respectively for the age groups 20 to 64 years, 65 years and above, and 20 years and above. Significant excess in mortality for circulatory diseases was observed across all age groups except for cerebrovascular accidents among females in the age group 65 years and above. 
Table 1: $\quad$ SMR, SIR and 95\% confidence intervals $(95 \% \mathrm{CI})$ for the age group 20 to 64 years.

\begin{tabular}{|c|c|c|c|c|}
\hline \multirow{2}{*}{ CAUSE (ICD-9) } & \multicolumn{4}{|c|}{ AGE 20 to 64 YEARS } \\
\hline & & Male & & Female \\
\hline 1. Mortality & & SMR $(95 \% C I)$ & No. & $\operatorname{SMR}(95 \% C I)$ \\
\hline Circulatory (390-459) & 2726 & $1.12(1.08,1.16)$ & 103 & $1.13(1.07,1.20)$ \\
\hline $\begin{array}{l}\text { Ischemic heart disease } \\
(410-414)\end{array}$ & 2004 & $1.10(1.05,1.14)$ & 557 & $1.10(1.01,1.19)$ \\
\hline $\begin{array}{l}\text { Cerebrovascular } \\
(430-438)\end{array}$ & 285 & $1.20(1.07,1.35)$ & 230 & $1.17(1.14,1.20)$ \\
\hline Respiratory (460-519) & 265 & $1.06(0.94,1.20)$ & 211 & $1.28(1.11,1.47)$ \\
\hline Pneumonia (480-486) & & $0.88(0.69,1.11)$ & 65 & $1.30(1.01,1.66)$ \\
\hline Influenza (487) & 2 & 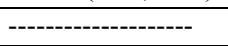 & 8 & 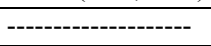 \\
\hline $\begin{array}{l}\text { Bronchitis/Emphysema } \\
(490-492)\end{array}$ & & $1.31(0.84,1.67)$ & & $1.67(1.09,2.44)$ \\
\hline Asthma (493) & & $0.89(0.50,1.47)$ & 28 & $1.22(0.81,1.76)$ \\
\hline Lung cancer (162) & 907 & $1.22(1.14,1.30)$ & 472 & $1.21(1.10,1.32)$ \\
\hline 2. Incidence & No. & $\operatorname{SIR}(95 \% C I)$ & No. & $\operatorname{SIR}(95 \% C I)$ \\
\hline Lung cancer (162) & 1185 & $1.19(1.12,1.26)$ & 678 & $1.18(1.09,1.27)$ \\
\hline
\end{tabular}

Table 2: $\quad$ SMR, SIR and 95\% confidence intervals $(95 \% \mathrm{CI})$ for the age group 65 years and above.

\begin{tabular}{|l|ll|ll|}
\hline \multirow{2}{*}{ CAUSE (ICD-9) } & \multicolumn{3}{|c|}{ AGE 65 YEARS AND OVER } \\
\cline { 2 - 6 } & \multicolumn{3}{|c|}{ Male } & \multicolumn{2}{c|}{ Female } \\
\hline 1. Mortality & No. & SMR $(95 \% C I)$ & No. & SMR $(95 \% C I)$ \\
\hline Circulatory (390-459) & 10629 & $1.16(1.14,1.18)$ & 12403 & $1.15(1.13,1.17)$ \\
\hline $\begin{array}{l}\text { Ischemic heart disease } \\
(410-414)\end{array}$ & 6915 & $1.17(1.14,1.20)$ & 7161 & $1.16(1.14,1.19)$ \\
\hline $\begin{array}{l}\text { Cerebrovascular } \\
(430-438)\end{array}$ & 1784 & $1.14(1.09,1.20)$ & 2510 & $1.02(0.98,1.06)$ \\
\hline Respiratory (460-519) & 1965 & $0.92(0.88,0.96)$ & 1515 & $0.83(0.79,0.88)$ \\
\hline Pneumonia (480-486) & 650 & $0.80(0.74,0.86)$ & 738 & $0.76(0.71,0.82)$ \\
\hline Influenza (487) & 11 & $0.54(0.27,0.96)$ & 25 & $0.66(0.43,0.97)$ \\
\hline $\begin{array}{l}\text { Bronchitis/Emphysema } \\
(490-492)\end{array}$ & 285 & $1.32(1.17,1.48)$ & 117 & $1.17(0.97,1.41)$ \\
\hline Asthma (493) & 42 & $1.37(0.99,1.85)$ & 44 & $0.92(0.67,1.24)$ \\
\hline Lung cancer (162) & 1661 & $1.10(1.05,1.15)$ & 743 & $1.03(0.96,1.11)$ \\
\hline 2. Incidence & No. & SIR $(95 \% C I)$ & No. & SIR $(95 \% C I)$ \\
\hline Lung cancer (162) & 1879 & $1.11(1.06,1.56)$ & 905 & $1.05(0.98,1.21)$ \\
\hline
\end{tabular}

Except for asthma, mortality from non-malignant respiratory diseases was significantly increased among females in the age group 20 to 64 years; excess mortality from bronchitis and emphysema remained statistically significant in the 
age group 20 years and above. In males, bronchitis and emphysema were significantly increased in the age groups 20 years and above and 65 years and above. With respect to lung cancer, significant excess mortality and incidence were noted across all age groups in males and females, except in the age group 65 years and over among females; SIR were highest in the 20 to 64 year age group in both genders.

Table 3: $\quad$ SMR, SIR and 95\% confidence intervals $(95 \% \mathrm{CI})$ for the age group 20 years and above.

\begin{tabular}{|l|ll|ll|}
\hline \multirow{2}{*}{ CAUSE (ICD-9) } & \multicolumn{3}{|c|}{ AGE 20 YEARS AND OVER } \\
\cline { 2 - 6 } & \multicolumn{3}{|c|}{ Male } & \multicolumn{2}{c|}{ Female } \\
\hline 1. Mortality & No. SMR $(95 \%$ CI) & No. & SMR $(95 \% C I)$ \\
\hline Circulatory (390-459) & 13355 & $1.15(1.13,1.17)$ & 13435 & $1.15(1.13,1.17)$ \\
\hline $\begin{array}{l}\text { Ischemic heart disease } \\
(410-414)\end{array}$ & 8919 & $1.15(1.13,1.17)$ & 7718 & $1.16(1.13,1.19)$ \\
\hline $\begin{array}{l}\text { Cerebrovascular } \\
\text { (430-438) }\end{array}$ & 2068 & $1.15(1.10,1.20)$ & 2740 & $1.03(1.00,1.07)$ \\
\hline Respiratory (460-519) & 2230 & $0.93(0.89,0.97)$ & 1726 & $0.87(0.83,0.91)$ \\
\hline Pneumonia (480-486) & 722 & $0.81(0.75,0.87)$ & 803 & $0.79(0.79,0.85)$ \\
\hline Influenza (487) & 13 & $0.60(0.32,1.03)$ & 25 & $0.64(0.42,0.95)$ \\
\hline $\begin{array}{l}\text { Bronchitis/Emphysema } \\
\text { (490-492) }\end{array}$ & 321 & $1.31(1.17,1.46)$ & 143 & $1.24(1.05,1.46)$ \\
\hline Asthma (493) & 57 & $1.20(0.91,1.55)$ & 72 & $1.02(0.80,1.28)$ \\
\hline Lung cancer (162) & 2568 & $1.14(1.09,1.18)$ & 1215 & $1.09(1.03,1.16)$ \\
\hline 2. Incidence & No. & SIR (95\%CI) & No. & SIR $(95 \% C I)$ \\
\hline Lung cancer (162) & 3064 & $1.14(1.10,1.18)$ & 1583 & $1.10(1.05,1.15)$ \\
\hline
\end{tabular}

\section{Discussion}

In the first phase of this project aimed at assessing the health effects of populations exposed to transborder air pollution, we have documented statistically significantly increased lung cancer incidence, and mortality from circulatory diseases, bronchitis and emphysema and from lung cancer in both males and females in Essex County; $82 \%$ of the population of Essex County is represented by the census metropolitan area of Windsor, a Canadian municipality located directly across the city of Detroit in the United States. These results are in keeping with those of studies of long-term exposure to air pollution that have shown excess cardiorespiratory mortality (Dockery et al. [16], Pope et al. [17, 18], Hoek et al. [19], Nafstad et al. [20]) and lung cancer mortality (Dockery et al. [16], Pope et al. [17, 18], Nafstad et al. [20], as well as lung cancer incidence Beeson et al. [21], Nyberg et al. [22], Nafstad et al. [23], and suggest a potential risk associated with air pollution exposure.

Our results have limitations inherent to mortality and cancer incidence studies. In particular no information on smoking and other important 
confounding variables such as occupation and diet is available to adjust for the excess risks observed. Currently, we are geocoding the mortality and cancer incidence data and collecting long-term information on air pollution measurements from monitoring station as well as on daily truck counts within the census metropolitan area of Windsor. The results of further planned studies that will assess chronic cardiorespiratory outcomes in relation to air and traffic pollution will be needed to provide stronger evidence for a potential relationship between exposure to air pollution and these health outcomes.

\section{References}

[1] Firket J. The cause of the symptoms found in the Meuse Valley during the fog of December 1931. Bull Acad R Med Belgium, 11, pp. 683-741, 1931.

[2] Ciocco A, Thompson DJ. A follow-up of Donora ten years after: methodology and findings. Am J Public Health, 51, pp. 155-164, 196.

[3] Logan WPD, Glasg MD. Mortality in London fog incident, 1952. Lancet, 1, pp. 336- 338, 1953.

[4] Schwartz J. Particulate air pollution and daily mortality in Detroit. Environ Res, 56, pp. 204-213, 1991.

[5] Schwartz J, Dockery DW. Increased mortality in Philadelphia associated with daily air pollution concentrations. Am Rev respir Dis, 145, pp. 600604, 1992.

[6] Schwartz J, Dockery DW. Particulate air pollution and daily mortality in Steubenville, Ohio. Am J Epidemiol, 135, pp. 12-19, 1992.

[7] Schwartz J. Air pollution and daily mortality in Birmingham, Alabama. Am J epidemiol, 137, pp. 1136-1147, 1993.

[8] Kinney PL, Özkaynak H. Associations of daily mortality and air pollution in Los Angeles County. Environ Res, 54, pp. 99-120, 1991.

[9] Dockery DW, Schwartz J, Spengler JD. Air pollution and daily mortality: associations with particulates and acid aerosols. Envrion Res, 59, pp. 362373, 1992.

[10] Samet JM, Dominici F, Curriero F, Coursac I, Zeger SL. Fine particulate air pollution and mortality in 20 U.S. cities, 1987-1994. New Engl $J$ Med, 343, pp. 1742-1749, 2000.

[11] Lipfert FW, Hammerstrom T. Temporal patterns in air pollution and hospital admissions. Environ Res, 59, pp. 374-399, 1992.

[12] Burnett RT, Dales RE, Raizenne ME, et al. Effects of low ambient levels of ozone and sulfates on the frequency of respiratory admissions to Ontario hospitals. Environ Res, 65, pp. 172-194, 1994.

[13] Burnett R, Dales R, Krewski D, Vincent R, Dann T, Brook JR. Associations between ambient particulate sulfate and admissions to Ontario hospitals for cardiac and respiratory diseases. Am J Epidemiol, 142, pp. 15-22, 1995. 
[14] Morris RD, Naumova E, Munasinghe RL. Ambient air pollution and hospitalization for congestive heart failure among elderly people in seven large US cities. Am J Public Health, 85, pp. 1361-1365, 1995.

[15] Schwartz J, Marcus A. Mortality and air pollution in London: a time series analysis. Am J Epidemiol, 131, pp. 185-194, 1990.

[16] Dockery DW, Pope A, Xiping X, Spengler JD, Ware JH, Fay ME, Ferris BG, Speizer FE. An association between air pollution and mortality in six U.S. cities. N Engl J Med, 329, pp. 1753-1759, 1993.

[17] Pope CA, Thun MJ, Namboodiri MM, Dockery DW, Evans JS, Speizer FE, Heath Jr CW. Particulate air pollution as a predictor of mortality in a prospective study of U.S. adults. Am J Respir Crit Care Med, 151, pp. 669-674, 1995.

[18] Pope CA, Brunett RT, Thun MJ, Calle EE, Krewski D, Ito K, Thurston GD. Lung cancer, cardiopulmonary mortality and long-term exposure to fine particulate air pollution. JAMA, 287, pp. 1132-1141, 2002.

[19] Hoek G, Brunekreef B, Goldbohm S, Fischer P, vand den Brandt PA. Association between mortality and indicators of traffic-related air pollution in the Netherlands: a cohort study. Lancet, 360, pp.1203-1209, 2002.

[20] Nafstad P, Håheim LL, Wisloff T, Gram F, Oftedal B, Holme I, Hjermann I, Leren P. Urban Air pollution and mortality in a cohort of Norwegian men. Environ Health Perspect, 112, pp. 610-615, 2004.

[21] Beeson WL, Abbey DE, Knutsen SF. Long-term concentrations of ambient air pollutants and incident lung cancer in California adults: results from the AHSMOG study. Environ Health Perspect, 106, pp. 813-823, 1998.

[22] Nyberg F, Gustavsson P, Järup, Bellander T, Berglind N, Jakobsson R, Pershagen G. Urban air pollution and lung cancer in Stockholm. Epidemiology, 11, pp. 487-495, 2000.

[23] Nafstad P, HåheimLL, Oftedal B, Gram F, Holme I, Hjermann I, Leren P. Lung cancer and air pollution: a 27 year follow up of 16209 Norwegian men. Thorax, 58, pp. 1071-1076, 2003.

[24] Breslow NE, Day NE. Statistical methods in cancer research. Volume2. The design and analysis of cohort studies. International Agency for Research on Cancer. IARC Scientific Publication no. 82: Lyon, 1987.

[25] World Health Organization. International Classification of Diseases. Manual of the international classification of diseases, injuries and causes of death. Ninth Revision. World Health Organization: Geneva, 1977.

[26] International Classification of Diseases for Oncology. Word Health Organization: Geneva, 1990. 